\title{
Doping of Bromine into Carbon Materials with Different Heat-Treatment Temperatures
}

\author{
Yoichi TAKAHASHI, Yasuko YOSHIKAWA, Noboru AKUZAWA* and Yasushi SONEDA** \\ Department of Applied Chemistry, Chuo University, 1-13-27, Kasuga, Bunkyo-ku, Tokyo 112-8551 \\ *Department of Chemical Science and Engineering, Tokyo National College of Technology, \\ 1220-2, Kunugidamachi, Hachioji-shi, Tokyo 193-0997 \\ **National Institute of Advanced Industrial Science and Technology, 16-1, Onogawa, Tsukuba-shi 305-8569
}

\author{
熱処理温度の異なる炭素材料への臭素のドーピング \\ 高橋洋一·吉川靖子 · 阿久沢 昇* . 曽根田 靖** \\ 中央大学理工学部応用化学科, 112-8551 東京都文京区春日 1-13-27 \\ *東京工業高等専門学校物質工学科, 193-0997 八王子市椚田町 1220-2 \\ **産業技術総合研究所， 305-8569 つくば市小野川 16-1
}

\begin{abstract}
Behavior of bromine doping into carbon materials with different heat-treatment temperatures (HTT) from 1000 to $2800^{\circ} \mathrm{C}$ were investigated, together with the characteristics such as XRD patterns, Raman spectra and electric conductivities of the respective bromine residue compounds prepared by debromination of the doped samples. It was found that there are two different cases in the behavior of the carbon materials for bromine doping depending on their HTTs; one is the carbons with high HTT $\left(\mathrm{HTT} \geqq 2000^{\circ} \mathrm{C}\right)$, the other those with low HTT (HTT $\leqq 1900^{\circ} \mathrm{C}$ ). The carbons of high HTT group form intercalation compounds with compositions up to $\mathrm{C}_{10} \mathrm{Br}$, and considerable fractions, such as $13-25 \%$, of the intercalated bromine remain in the interlayer space of graphite after the debromination process, thus forming the bromine residue compounds. On the other hand, the carbons of HTT $\leqq 1900^{\circ} \mathrm{C}$, except for HTT1000, absorb only small amounts of bromine, which are almost completely expelled by the debromination process. They apparently do not form residue compounds with bromine. The carbon with HTT1000 was found to have an unique character: It absorbed an appreciable amount of bromine and the remaining fraction of the bromine after debromination was rather large, although the XRD pattern and the electric conductivity were unchanged. It is thus suggested that the remaining bromine may exist on the edge of the crystallites by forming weak bonding with carbon atoms.
\end{abstract}

[Received September 9, 2002; Accepted November 6, 2002]

Key-words : Graphite intercalation compound, Bromine-graphite residue compound, Br-doping, XRD pattern, Raman spectra

\section{Introduction}

The graphite intercalation compound with bromine has been studied extensively ${ }^{1)-3}$ because of the ease of its synthesis, high electric conductivity of the resulting compound and the existence of the residue compound. In particular, the high electric conductivity and the unusual stability of the residue compound have attracted attention of many investigators in the field of carbon fiber technology. ${ }^{4)-6)}$ However, studies on the bromine-carbon system with emphasis on the effect of graphitization degree of host carbons are rare. Mukaibo and Takahashi ${ }^{7}$ studied on the samples of artificial graphite heat-treated at $800,1500,2000$ and $2600^{\circ} \mathrm{C}$ and found that for the samples heat-treated above $1500^{\circ} \mathrm{C}$, both the saturated amount of absorbed bromine and absorption rate increased with the heat-treated temperature, whereas the sample heat-treated at $800^{\circ} \mathrm{C}$ had exceptionally large bromine absorption, almost twice as much as that of the sample heat-treated at $1500^{\circ} \mathrm{C}$. Hooley and Deitz, ${ }^{8)}$ and Mathur et al. ${ }^{9)}$ also pointed out, in their studies using carbon fibers, that intercalation of bromine became difficult with the carbon fiber samples having low graphitization degree. A systematic investigation on the behavior of bromine doping into samples with different degree of graphitization has not been hitherto seen.

We have recently reported ${ }^{10)}$ some results of IBr doping into several carbon samples of different heat-treatment temperature, in view of their electric conductivity change. Here, we report on the host-effect of bromine doping into the carbon samples with different heat-treatment temperatures, which are the same materials used for the $\mathrm{IBr}$ doping study. ${ }^{10)}$

\section{Experimental}

The carbon samples used were taken from artificial graphite kindly provided by SEC Corp., which were derived from petroleum coke particles with a pitch binder and heat-treated at about $1000^{\circ} \mathrm{C}$ (hereafter designated as HTT1000). Small blocks of the raw graphite were then heat-treated at respective temperatures of 1500, 1750, 1900, $2000,2200,2400$ and $2800^{\circ} \mathrm{C}$ (HTT1500-HTT2800). Bromine with purity of $>99 \%$ (Wako Junyaku Kogyo Co.) was used after distillation in vacuum.

Specimens $(2 \times 3 \times 20 \mathrm{~mm})$ of each carbon sample were placed in an evacuated glass reaction vessel equipped with a bromine reservoir, and doping of bromine was made by allowing the specimens to contact with saturated bromine vapor at room temperature for several hours until the saturation of bromine absorption was achieved. The amount of bromine absorption was determined by observing the lowering of liquid bromine level in an upper capillary part of the bromine reservoir. The saturated compounds thus prepared were debrominated by cooling the bromine reservoir to liquid nitrogen temperature and then heating the sample in a vacuum of $10^{-1} \mathrm{~Pa}$ at $300^{\circ} \mathrm{C}$ for several hours to complete the debromination. The resulting bromine residue compounds were confirmed to be quite stable in the air. For the carbon samples of HTT2200, 2400 and 2800, the bromine absorption process was performed under several controlled 
bromine vapor pressures $(P)$ such as $P / P_{0}=0.5$ and 0.25 , where $P_{0}$ is the saturated vapor pressure of the sample temperature, and the residue compounds of each were prepared in the same way. The compositions of the residue compounds were determined from the weight increase of the specimens.

The measurements of X-ray diffraction (XRD) (Rigaku RINT2000, $\mathrm{Cu} \mathrm{K} \alpha$ ), Raman spectroscopy (Renishaw Raman Microscopy System 2000, He-Ne laser), electric conductivity (four-terminal method) and thermoelectric power were made on each residue compounds.

\section{Results and discussion}

3.1 Doping of bromine into carbons with different heat-treatment temperatures and their bromine residue compounds

The concentrations of absorbed bromine at saturation into the carbon samples of different HTT under the saturated bromine pressure at room temperature are shown in Fig. 1, together with those of remaining bromine after the debromination process. For the host carbons of $\mathrm{HTT} \geqq 2000^{\circ} \mathrm{C}$, the concentration of absorbed bromine at saturation increased with HTT of the host carbon and the atomic ratio of bromine to carbon, $\left(n_{\mathrm{Br}} / n_{\mathrm{C}}\right)$, became $0.08-0.1$. The saturation composition for HTT2800 carbon becomes nearly $\mathrm{C}_{10} \mathrm{Br}$. This can be compared with the literature values for artificial graphites, ${ }^{7)}$ whereas for well graphitized carbons such as natural graphite, the saturation composition is known to be $\mathrm{C}_{8} \mathrm{Br} .{ }^{1), 2)}$ On the other hand, for the carbons of HTT $\leqq 1900^{\circ} \mathrm{C}$, it decreased with HTT and the values of $\left(n_{\mathrm{Br}} /\right.$ $\left.n_{\mathrm{C}}\right)$ at saturation were rather small, less than 0.03 .

As for the residue compounds after debromination treatment, again rather different behavior was seen between the host carbons of high HTT and of low HTT. For the residue compounds prepared from carbons of $\mathrm{HTT} \geqq 2000^{\circ} \mathrm{C}$, the concentrations of remaining bromine were appreciable, $\left(n_{\mathrm{Br}} / n_{\mathrm{C}}\right)=0.01-0.02$, which were $20-25 \%$ of those at saturation, though HTT2800 has a little small remaining fraction of bromine of about $13 \%$. On the other hand, the remaining fractions for the carbons of HTT1500-HTT1900 were fairly small, virtually zero.

The X-ray diffractgrams of the host carbons and the bromine residue compounds are shown in Fig. 2. The usual graphitization behavior with increasing heat-treatment temperature was observed for the host carbons. The residue compounds prepared from the samples of $\mathrm{HTT} \leqq 1900^{\circ} \mathrm{C}$ showed very similar patterns to the respective host carbons, while the peak positions of the residue compounds from the samples of $\mathrm{HTT} \geqq 2000^{\circ} \mathrm{C}$ shifted appreciably towards lower diffraction angles, indicating that the interlayer distance is slightly expanded by the remaining bromine. Since any indications of higher stages were not recognized in the patterns, these bromine molecules are considered to be randomly distributed in the interlayer spaces of the host carbons.

As stated above, the mechanisms of bromine doping are clearly different between the cases of low HTT and high HTT carbons, and the boundary of the two cases seems to lie between 1900 and $2000^{\circ} \mathrm{C}$. For the samples of high HTT carbons, bromine molecules are considered to be intercalated in the interlayer space of graphite in the similar way to other ordinary graphite intercalation compounds, and in this case a considerable fraction of the intercalated bromine still remain in the interlayer spaces in the residue compounds after the debromination process. On the other hand, the samples of low HTT carbons, except for that of HTT1000, absorb rather small amounts of bromine even under saturated bromine pressure, and their remaining fractions after debromination process are very small. The results of XRD

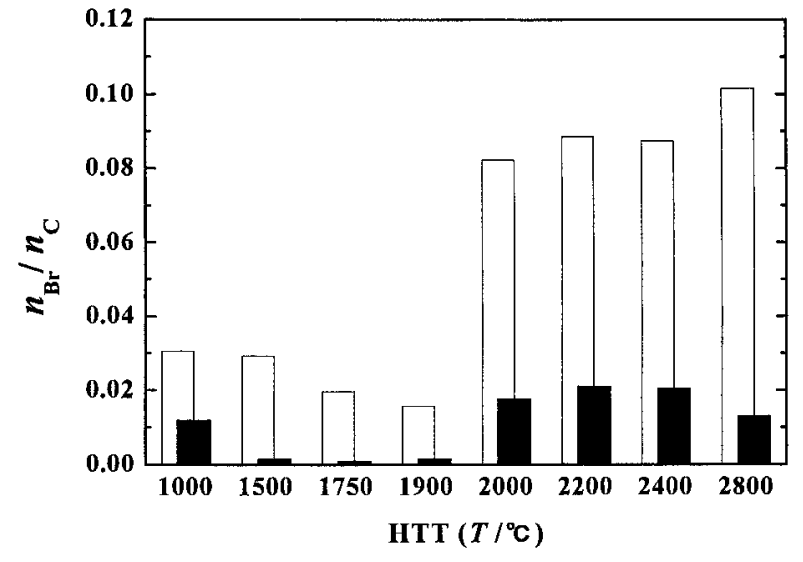

Fig. 1. Bromine concentrations in saturation and residue compounds. $\square$ : in saturation, $\square$ : in residue.

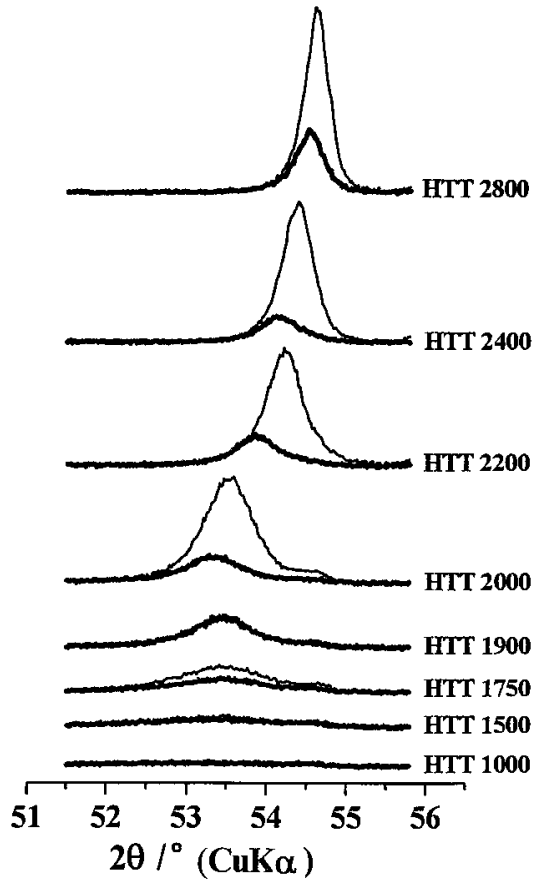

Fig. 2. XRD patterns of host carbons and bromine residue compounds. $\longrightarrow$ : host carbons, $\longrightarrow$ : residue compounds.

measurements also suggest that for low HTT carbons there exist no bromine molecules in the interlayer space. For the sample of HTT1000, discussion will be made in Sec. 3.5.

3.2 Electric conductivity of the residue compounds

The residue compounds prepared from the host carbons of $\mathrm{HTT} \leqq 1900^{\circ} \mathrm{C}$ showed almost the same electric conductivity as the respective host carbons, in accord with their virtually negligible remaining bromine as stated in the preceding section, while an appreciable increase in electric conductivity by bromine doping was observed on the host carbons of $\mathrm{HTT} \geqq 2000^{\circ} \mathrm{C}$. Similar behavior was also reported ${ }^{10)}$ for IBr doping into the same host carbons. For the high HTT carbons, the dependence of bromine concentration in the residue compounds upon their electric conductivity was examined by controlling the relative bromine pressure $\left(P / P_{0}\right)$. In Fig. 3 the results are shown as the relative electric conductivity $\left(\sigma / \sigma_{0}\right)$ vs. the bromine concentration of the 


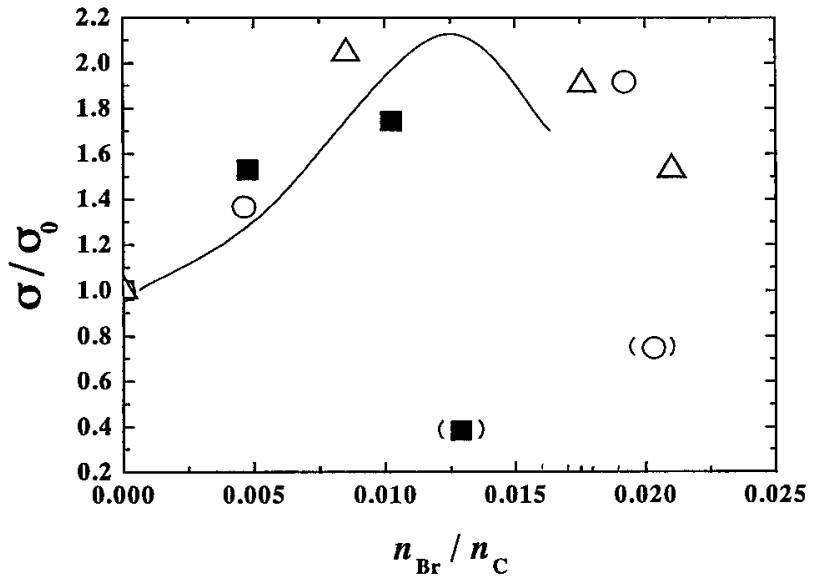

Fig. 3. Relative electric conductivity vs. bromine concentration of residue compounds. $\triangle$ : HTT2200, $\bigcirc$ : HTT2400, $\mathbf{\text { : }}$ : HTT2800, : Sasa et al. ${ }^{11}$

residue compounds, where $\sigma_{0}$ is the electric conductivity of the respective host carbons. As shown in Fig. 3, these results on the samples of different HTTs agree fairly well with those of Sasa et al., ${ }^{11)}$ though they used well-graphitized carbons such as heat-treated pyrolytic graphites. Among the residue compounds, two samples of $n_{\mathrm{Br}} / n_{\mathrm{C}}>$ 0.012 showed the values of $\left(\sigma / \sigma_{0}\right)$ less than one, which are indicated in parentheses in Fig. 3. It is probably because that the specimens of these samples would have some cracks in their structure during the process of bromine intercalation owing to large expansion of interlayer distances, as was indicated by Hennig. ${ }^{2)}$ Except for these two samples, the effects of bromine concentration on the electric conductivity are almost similar, irrespective of heat-treatment temperature of host carbons. This fact suggests that the main part of remaining bromine molecules exist in the interlayer space and contribute to the increase of charge carrier of the residue compounds, in accord with the conclusion of Miyauchi and Takahashi. ${ }^{12)}$

The temperature dependence of the electric conductivity was also examined from 80 to $450 \mathrm{~K}$ on each residue compound. The samples of $\mathrm{HTT} \leqq 1900^{\circ} \mathrm{C}$ showed the same temperature dependence as the respective host carbons, whereas for those of $\mathrm{HTT} \geqq 2000^{\circ} \mathrm{C}$ it was observed a tendency to shift to metallic behavior from semi-conductive one of the host carbons.

3.3 Raman spectra of the bromine residue compound Raman spectra of the host carbons of different heat-treatment temperature showed the ordinary tendency to change, similarly to the results of XRD measurement, with increasing HTT. We observed so-called G-, D-, and $\mathrm{D}^{\prime}$-band at around 1580, 1330 and $1620 \mathrm{~cm}^{-1}$, respectively. The frequency of D-band, around $1330 \mathrm{~cm}^{-1}$, is fairly low as compared with the normally observed value of $1360 \mathrm{~cm}^{-1}$. This shift is attributable to the fact that the exciting wave-length of the He-Ne laser used in this experiment is $632.8 \mathrm{~nm}$ and considerably long as compared with $514.5 \mathrm{~nm}$ of $\mathrm{Ar}^{+}$laser usually used. ${ }^{13)}$

The Raman spectra of the residue compounds prepared from the carbons of low HTT were found to be almost the same as those of the host carbons. On the other hand, for the residue compounds prepared from the HTT2400 and HTT2800 carbons, the intensities of D-band and $\mathrm{D}^{\prime}$-band, at around 1330 and $1620 \mathrm{~cm}^{-1}$, respectively, were observed to decrease with the concentration of the remaining bromine. Figure 4 shows the Raman spectra of the HTT2800 host

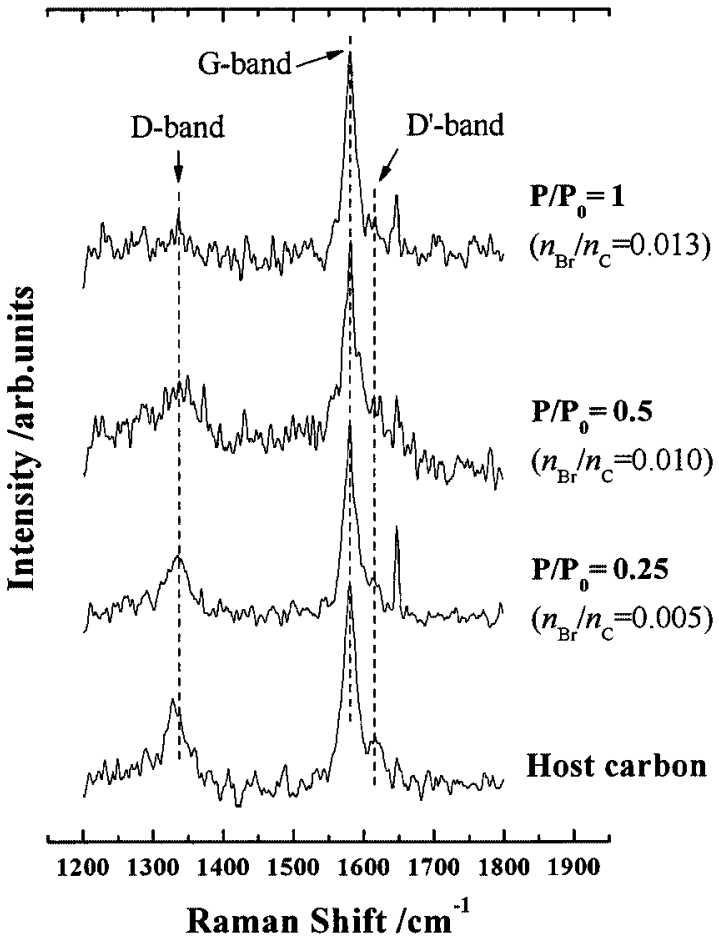

Fig. 4. Raman spectra of HTT2800 host carbon and its bromine residue compounds.

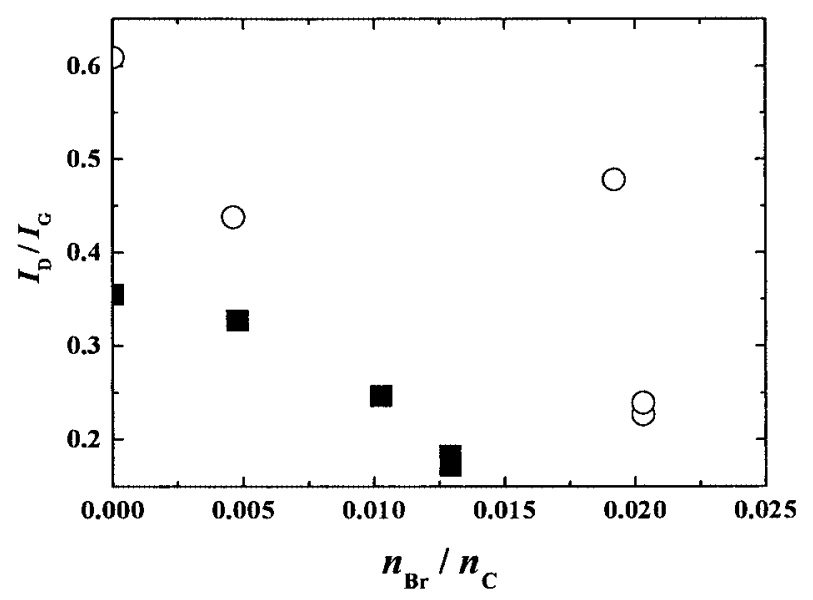

Fig. 5. Relative Intensity $\left(I_{\mathrm{D}} / I_{\mathrm{G}}\right)$ vs. bromine concentration of residue compounds. $\bigcirc$ : HTT2400, ㅁ: HTT2800.

carbon and its bromine residue compounds. It is to be noted that in the spectra of Fig. 4, a small sharp peak at around $1650 \mathrm{~cm}^{-1}$ are seen near the $\mathrm{D}^{\prime}$-band at $1620 \mathrm{~cm}^{-1}$. This peak is considered to be caused by undesirable instrumental stray light and is to be disregarded. In Fig. 5, the changes of the relative intensity, $I_{\mathrm{D}} / I_{\mathrm{G}}$, of $\mathrm{D}$-band to G-band with the bromine concentration are shown on the residue compounds of HTT2400 and HTT2800. The decreasing tendency of $I_{\mathrm{D}} /$ $I_{\mathrm{G}}$ with bromine concentration indicates that the bromination-debromination process apparently caused some rearrangements in the texture of the host carbons because of the large expansion of interlayer distances by the intercalation of bromine molecules. It is to be added here that the results on the same samples which we showed in parentheses in Fig. 3 were also included in Figs. 4 and 5, and they showed 
the normal, similar behavior to other samples of the residue compounds.

Song et al. ${ }^{14)}$ reported that in the Raman spectra of the graphite-bromine compound $\left(n_{\mathrm{Br}} / n_{\mathrm{C}}=0.0114\right)$ prepared from highly oriented pylorytic graphite (HOPG), the G-band peak at $1580 \mathrm{~cm}^{-1}$ splitted into a doublet signal at around $1580 \mathrm{~cm}^{-1}$ and $1600 \mathrm{~cm}^{-1}$. They studied also on $\mathrm{ICl}$-, $\mathrm{IBr}^{-}, \mathrm{HNO}_{3}$-graphite system as well as on $\mathrm{Br}_{2}$-graphite, and revealed that this doublet signal was observed commonly on these intercalation and/or residue compounds. In the present study, we also observed the doublet signals, which appeared at around 1580 and $1596 \mathrm{~cm}^{-1}$ for HTT2400, and at 1580 and $1593 \mathrm{~cm}^{-1}$ for HTT2800. These bands showed a tendency to shift towards slightly higher wave length, with the bromine concentration in the samples, in accord with the results of Song et al. ${ }^{14}$

3.4 Thermoelectric power of the bromine residue compounds

The experimental results of thermoelectric power measurements at $273 \mathrm{~K}$ are shown in Fig. 6 against the bromine concentration in the residue compounds. Although Fig. 6 shows some scatter, it is seen that the absolute thermoelectric power tends to increase at first with the bromine concentration, probably because of the increase of positive holes as the charge carrier in the samples, and then for $n_{\mathrm{Br}} /$ $n_{\mathrm{C}}$ above 0.01 , it appears to converge on $30-45 \mu \mathrm{V} \mathrm{K}^{-1}$, irrespective of HTT of the host carbons. The samples shown in parentheses in Fig. 3, which were considered to have some cracks, showed the values slightly lower than the average, but in general their behavior was almost the same as other samples. The temperature dependence of thermoelectric power was also found to increase with the bromine concentration.

\subsection{Bromine doping into the carbon of HTT 1000}

The behavior of the carbon of HTT1000 upon bromine doping was unique as compared with that of the other low HTT carbons. Namely, the concentration of absorbed bromine under the saturated bromine pressure was comparatively small, whereas the remaining fraction of bromine after debromination process was considerably large and was more than $30 \%$. Similar unusual behavior was also reported by Mukaibo and Takahashi. ${ }^{7}$ on the carbon sample heattreated at $800^{\circ} \mathrm{C}$. Nevertheless, the XRD patterns of the residue compound were found to be almost the same as those of the host HTT1000 carbon. It was also found that

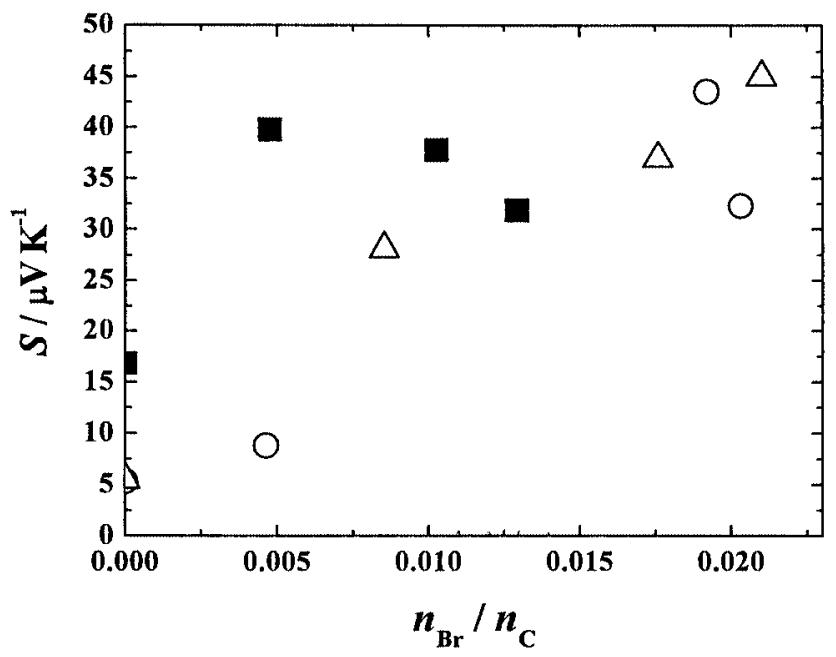

Fig. 6. Thermoelectric power vs. bromine concentration of residue compounds. $\triangle$ : HTT2200, $\bigcirc$ : HTT2400, घ: HTT2800. there was negligibly small effect on the electric conductivity. These observations indicate that the remaining bromine molecules in the HTT1000 carbon do not exist in the interlayer space. The bromine molecules are considered to make weak bonding with the carbon atoms at the edge of the crystallite of the host carbon.

\section{Conclusions}

The behavior of bromine doping into carbon materials of artificial graphite derived from petroleum coke and heattreated at several different temperatures from 1000 to $2800^{\circ} \mathrm{C}$ (designated as HTT1000 etc.) was investigated. The characteristics of the bromine residue compounds after the debromination process of the respective bromine-carbon system were also examined. The results are summarized as follows.

(1) For the carbons of $\mathrm{HTT} \leqq 1900^{\circ} \mathrm{C}$, except for HTT1000, the concentrations of absorbed bromine under the saturated bromine pressure were rather small, and the remaining fractions of the bromine after the debromination process were virtually zero. It is considered that the bromine residue compounds are hardly formed for these low HTT carbons.

(2) The carbons of $\mathrm{HTT} \geqq 2000^{\circ} \mathrm{C}$ were found to absorb bromine under the saturated bromine pressure up to $n_{\mathrm{Br}} / n_{\mathrm{C}}$ $\cong 0.1$, and the remaining fractions of the bromine after the debromination process were $13-25 \%$ of the saturation concentrations, thus resulting the bromine residue compounds.

(3) In the bromine residue compounds, the main part of the bromine molecules are considered to exist in random distribution in the interlayer space of the graphite, and contribute apparently by charge transfer to the increase in the electric conductivity, irrespective of HTT of host carbons.

(4) The thermoelectric powers of the residue compounds of $n_{\mathrm{Br}} / n_{\mathrm{C}} \geqq 0.01$ were found to converge on the value $30-45 \mu \mathrm{V} \mathrm{K}^{-1}$, irrespective of HTT of the host carbons.

(5) The carbon sample of HTT1000 showed an unique character in the behavior for bromine doping. It absorbed an appreciable amount of bromine under the saturated bromine pressure, and considerable fraction of the bromine remained after the debromination process. In this case, however, little effects on the electric conductivity and the XRD pattern were observed, and consequently the bromine molecules are considered to exist not in the interlayer space of the graphite, but probably on the edge of the crystallites by forming weak bonding.

Acknowledgement The authors would like to express their thanks to Prof. Keiko Nishikawa, Chiba University, for her helpful discussion on this study. The authors are also grateful to $\mathrm{Mr}$. Teruhiro Tsurumoto of SEC Corp. for providing carbon materials.

1) Rüdorff, W., Z. Anorg. Allg. Chem., Vol. 245, pp. 383-390 (1941).

2) Hennig, G., J. Chem. Phys., Vol. 20, pp. 1443-1447 (1952).

3) Sasa, T., Takahashi, Y. and Mukaibo, T., Carbon, Vol. 9, pp. 407-416 (1971).

4) Dowell, M. B., Mater. Sci. Engng., Vol. 31, pp. 129-136 (1977).

5) Gaier, J. R. and Jaworske, D. A., Synth. Metals, Vol. 12, pp. 525-532 (1985).

6) Ho, C.T. and Chung, D. D. L., Carbon, Vol. 27, pp. 603-609 (1989).

7) Mukaibo, T. and Takahashi, Y., Kogyo Kagaku Zasshi, Vol. 65, pp. 754-758 (1962) [in Japanese].

8) Hooley, J. G. and Deitz, V. R., Carbon, Vol. 16, pp. 251-257 (1978).

9) Mathur, R. B., Bahl, O. P., Kannan, A., Flandrois, S., Marchand, A. and Gupta, V., Carbon, Vol. 34, pp. 1215-1220 (1996). 
10) Akuzawa, N., Kaneko, K., Miyata, N., Soneda, Y. and Takahashi, Y., Tanso, Vol. 1999 (No. 190), pp. 229-232 (1999).

11) Sasa, T., Takahashi, Y. and Mukaibo, T., Bull. Chem. Soc. Japan, Vol. 43, pp. 34-38 (1970).

12) Miyauchi, K. and Takahashi, Y., Carbon, Vol. 14, pp. 35-38
(1976)

13) Katagiri, G., Tanso, Vol. 1996 (No. 175), pp. 304-313 (1996) [in Japanese].

14) Song, J. J., Chung, D. D. L., Eklund, P. C. and Dresselhaus, M. S., Solid State Commun., Vol. 20, pp. 1111-1115 (1976). 